\title{
THE USE OF TRIAL SCALE IN A PEDIATRIC EMERGENY DEPARTEMENT
}

\section{D.Fellah, R.Guedri, R.Hammami, L.Essaddem, N.Mattoussi, Z.Fitouri, S.Ben Becher \\ Pediatric,Emergency and consultation Departement \\ Child Hospital Bechir Hamza ,Tunis, Tunisia}

\section{BACKGROUND AND AIMS :}

We aim to prove the advantage of a trial scale in the management of pediatric emergency cases The use of trial scale is a strategy Key for faster treatment for the patient with severe clinical condition.

\section{METHOD :}

We conducted a prospective and descriptive study in the emergency department of the Tunisian child hospital. We used the French trial scale of the Timone child Hospital that was easier to assess his 3 stages.

The reason of consultation, waiting time, duration of the consultation and patient's care were noted. We compared nurse stage to doctor's one .The waiting time before and after the use of trial scale were noted.

\section{RESULTS :}

We identified 810 patients. The average age was 40.27 months. sex ratio was 0.85 . For $91 \%$ parents consult without medical advice. They consult for fever (42.6\%) and respiratory disease $(41.3 \%)$ (Chart 1$)$. The third stage was the most frequent (75.1\%) (Chart 2). The mean of consultation's time, waiting time and lentgh of stay were respectively $7.7 \mathrm{~min}, 73.43 \mathrm{~min}$ and $81.97 \mathrm{~min}$. We required further examinations for $9.5 \%$ of patients: biological (45\%) and radiological (28\%). Expert medical advice needed for $5.6 \%$. Admission rate was only $16.9 \%($ Chart 3,4).

The nurse staging matchs the doctor's one in $82 \%$ (Chart 5 ).

The difference between waiting time and the lentgh of stay before and after using the trial scale was statistically significant $p<0.001$. We gain $22.5 \mathrm{~min}$ in waiting time and $24.6 \mathrm{~min}$ in the lentgh of stay(Chart 6,7 ).

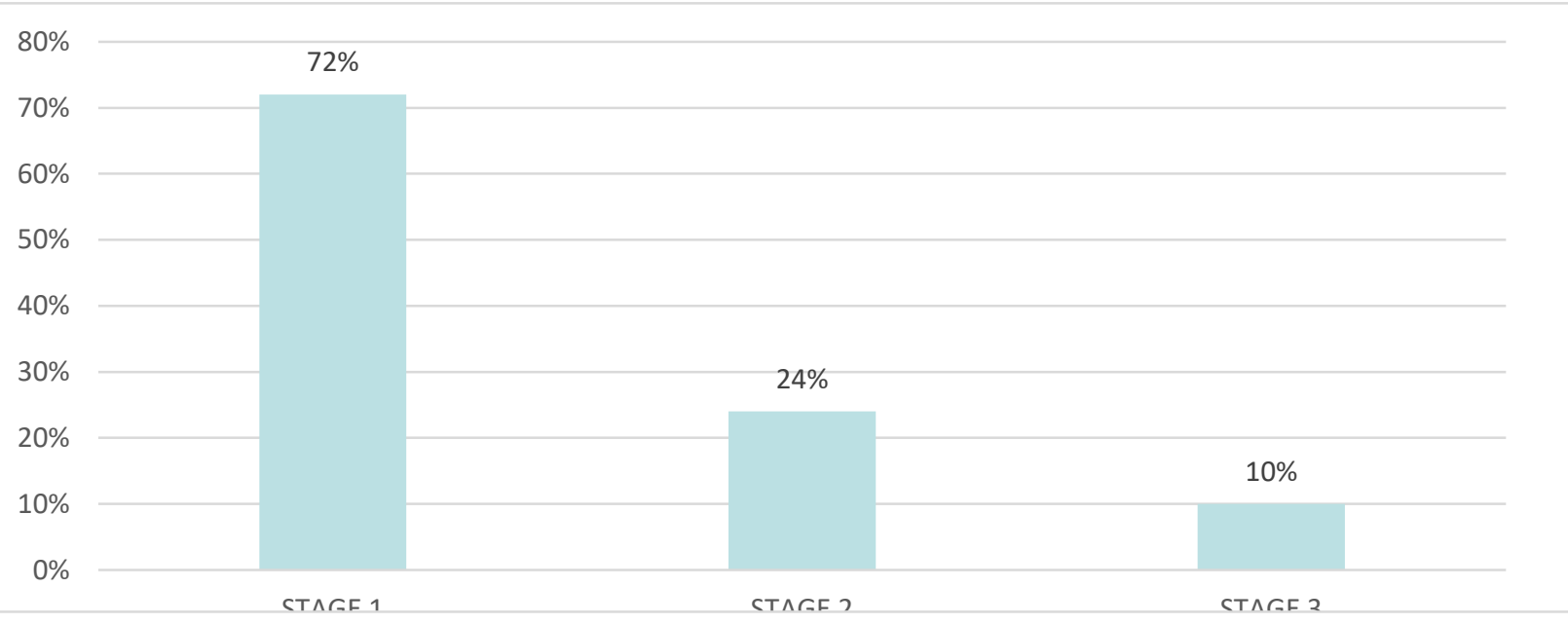

Chart 4 : Admission rate according to the stage of severity

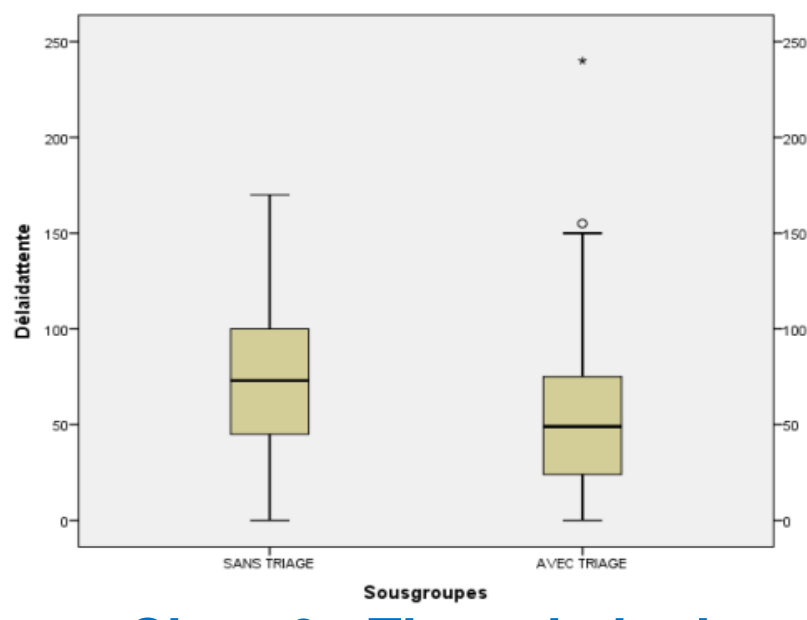

Chart 6 : The gain in the wainting time

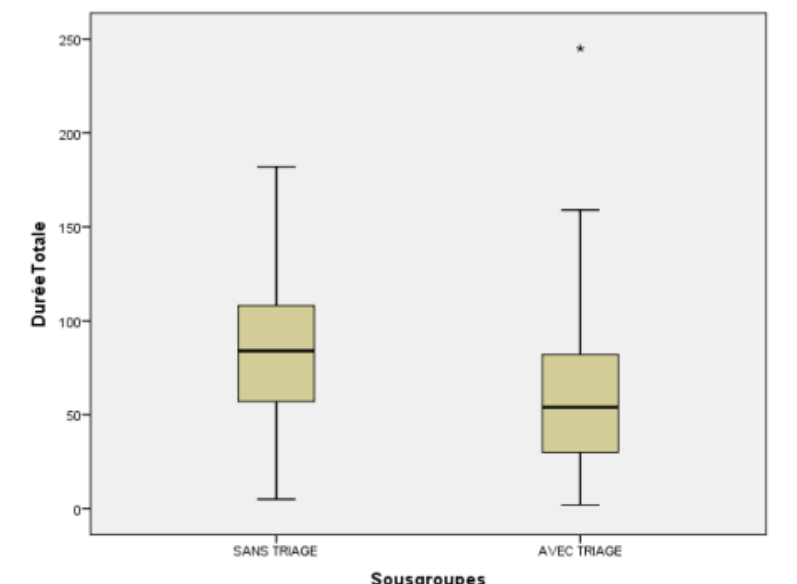

Chart 7 : The gain in the Lentgh of stay

\section{CONCLUSION :}

Using the trial scale has resulted in a better management of pediatric emergency departement while having a descriptive and prognosis view. We concluded that real emergencies were dissenting. Therefore, parents should be aware of the importance of reducing non-emergency consultations in order to improve emergency care.

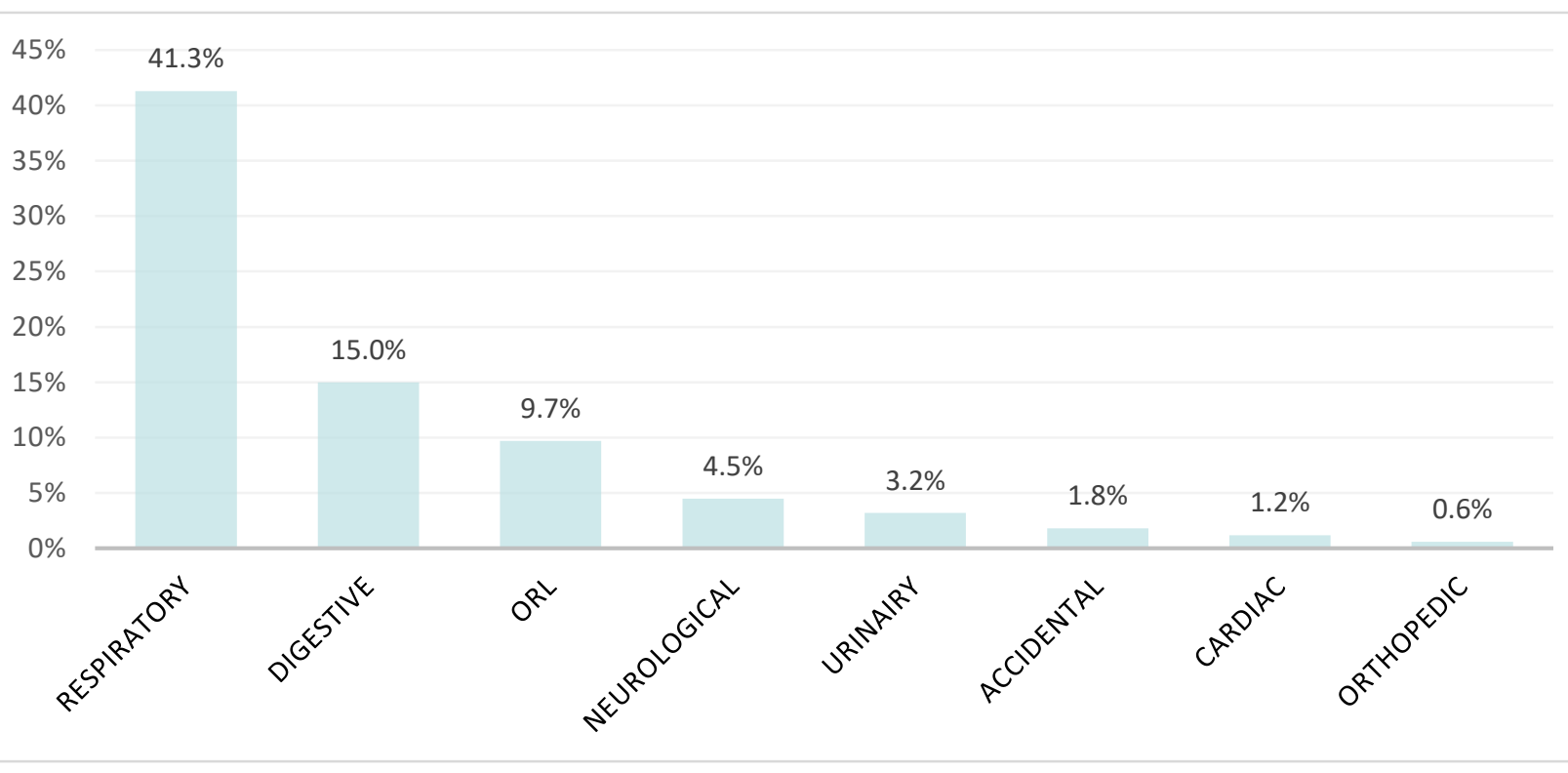

Chart 1 : Reasons of consultation

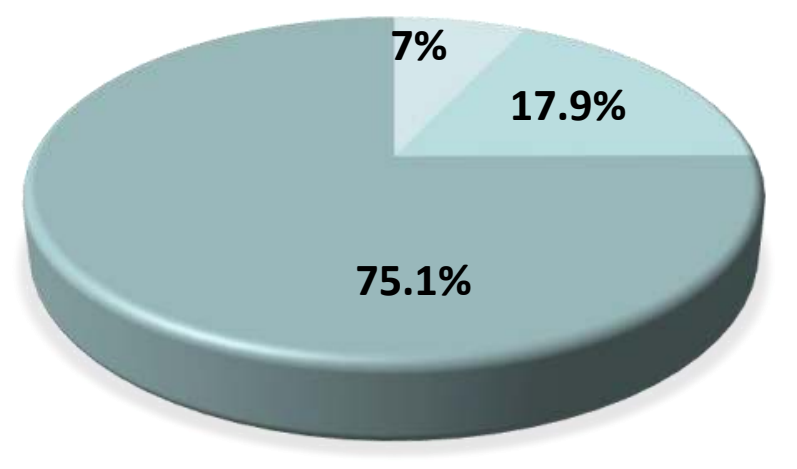

ASTAGE 1

MSTAGE 2 $\triangle$ STAGE 3

Chart 2 : Stages of severity
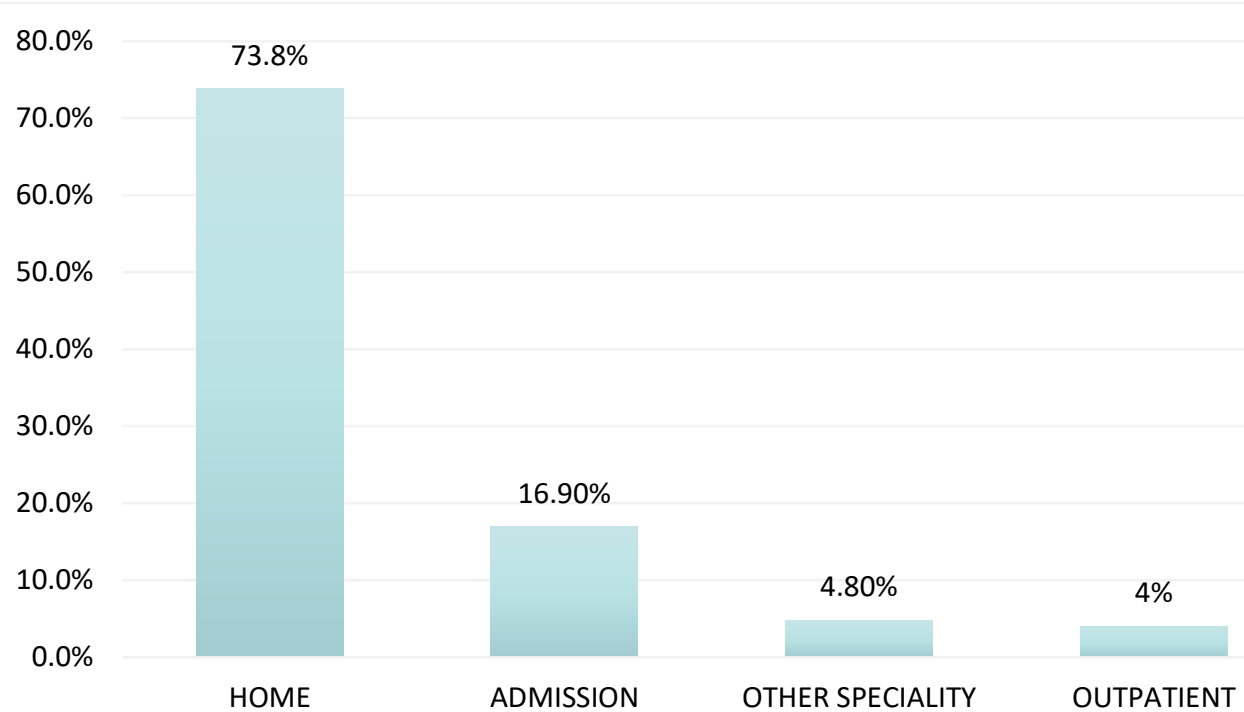

OUTPATIENT

Chart 3 : Patients' Outcome
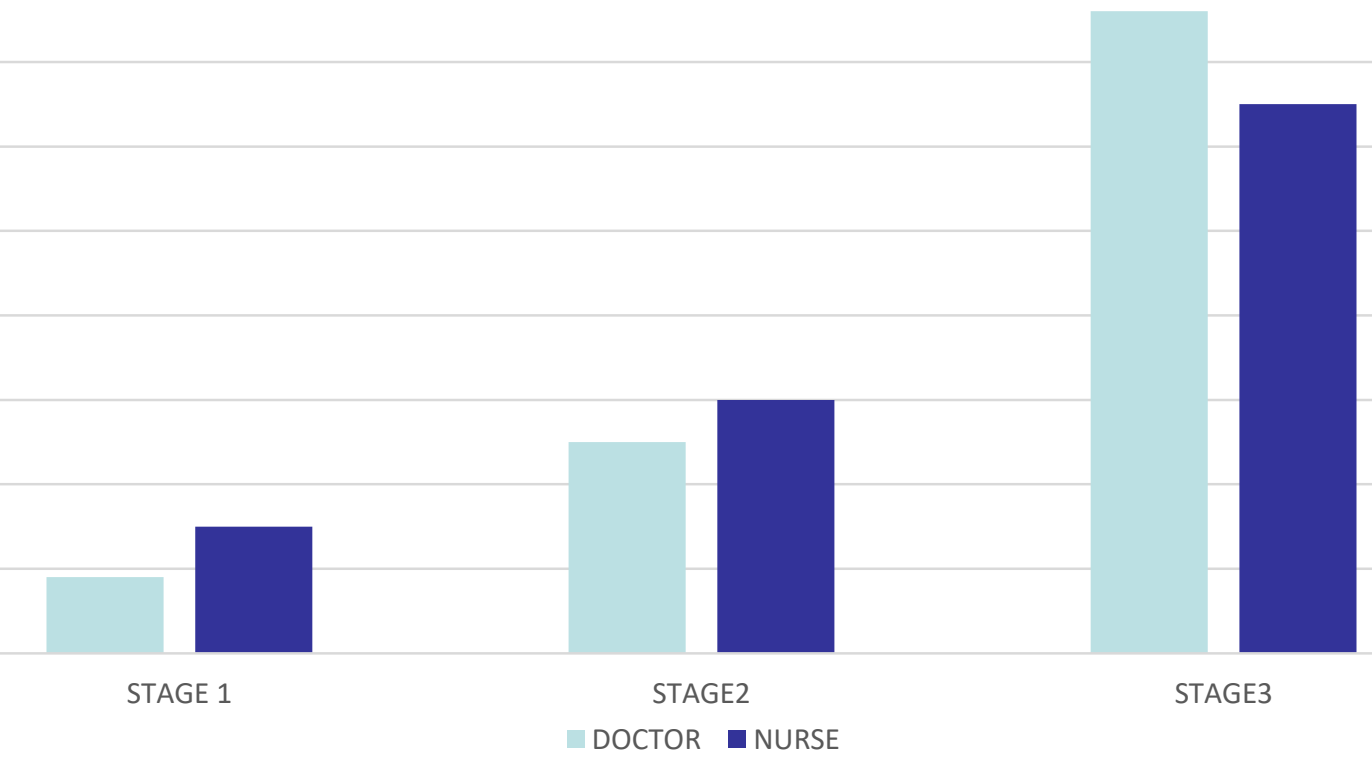

Chart 5 :Comparaison between doctor and nurse stage Copyright $\odot 2017$ Author Names and Contact Details 